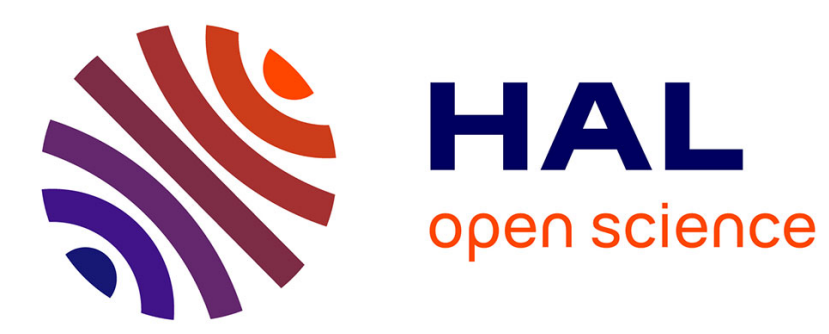

\title{
Nanostructured Silicon Thin Films Deposited Under Dusty Plasma Conditions
}

\author{
Marjorie Cavarroc, Maxime Mikikian, Yves Tessier, Laifa Boufendi
}

\section{To cite this version:}

Marjorie Cavarroc, Maxime Mikikian, Yves Tessier, Laifa Boufendi. Nanostructured Silicon Thin Films Deposited Under Dusty Plasma Conditions. IEEE Transactions on Plasma Science, 2008, 36 (4), pp.1016. 10.1109/TPS.2008.920889 . hal-00312605

\section{HAL Id: hal-00312605 https://hal.science/hal-00312605}

Submitted on 25 Aug 2008

HAL is a multi-disciplinary open access archive for the deposit and dissemination of scientific research documents, whether they are published or not. The documents may come from teaching and research institutions in France or abroad, or from public or private research centers.
L'archive ouverte pluridisciplinaire HAL, est destinée au dépôt et à la diffusion de documents scientifiques de niveau recherche, publiés ou non, émanant des établissements d'enseignement et de recherche français ou étrangers, des laboratoires publics ou privés. 


\title{
Nanostructured Silicon Thin Films Deposited Under Dusty Plasma Conditions
}

\author{
Marjorie Cavarroc, Maxime Mikikian, Yves Tessier, and Laïfa Boufendi
}

\begin{abstract}
Silane-based dusty plasmas are widely used in plasma-enhanced chemical vapor deposition processes to synthesize silicon nanoparticles and/or nanostructured thin films. Under certain conditions, it is possible to access to the inner structure of the thin film by scanning electron microscopy, using the "hole" due to dust particles that moved when the sample is brought back to atmospheric pressure.
\end{abstract}

Index Terms-Dust particle, dusty plasma, nanostructured thin film, PECVD, radio frequency (RF) discharge, silicon.

D USTY PLASMAS generated in radio frequency (RF) discharges are widely studied since the 1990s. A first burst of interest has been induced by the contamination due to dust particles in industrial plasma reactors. In the 2000s, a second burst of interest appears due to the potential applications of silicon nanocrystals and nanostructured thin films.

Right now, dust formation in silane-based plasmas is relatively well understood and well controlled. The first dust generation is known to grow according to a four-step process [1]-[3], whereas it has been shown recently that the following generations are growing according to a three-step process, as long as silane precursors are provided in the discharge [4].

The experimental setup used to perform the depositions is a typical plasma-enhanced chemical vapor deposition chamber with a plasma box enclosed inside $(13 \mathrm{~cm}$ inner diameter and $3 \mathrm{~cm}$ height corresponding to the gap). The powered electrode ( $\mathrm{RF}$ electrode: $13.56 \mathrm{MHz}$ ) is a showerhead one in order to ensure a homogeneous gas distribution in the plasma box, which is grounded. Typical experimental conditions are a gas mixture composed of $8 \%$ silane diluted in pure argon, under a pressure of $12 \mathrm{~Pa}$, at room temperature.

Samples shown in Fig. 1 have been deposited as follows. The silicon (100) substrates were located on the grounded electrode. Plasma conditions were the ones presented in the previous section, and the process was stopped during the third generation of dust particles (monitored by using an electrical diagnostics). Samples were then analyzed by using scanning electron microscopy (SEM).
Manuscript received November 29, 2007; revised February 8, 2008.

The authors are with the Groupe de Recherches sur l'Energétique des Milieux Ionisés (GREMI), CNRS-Université d'Orléans, 45067 Orléans Cedex 2, France (e-mail: maxime.mikikian@univ-orleans.fr).

Digital Object Identifier 10.1109/TPS.2008.920889
Images shown in Fig. 1 allow one to access to the thin film structure and to get an insight in the dust cloud structure during the process. Fig. 1(b) shows a SEM picture of the layer of the deposition with a scale of $200 \mathrm{~nm}$. It gives an overview of the layer structure. We can evidence that it is made of small silicon clusters around $20 \mathrm{~nm}$ in diameter. This layer appears to be quite dense. Numerous nanoclusters overlap all over the sample. Fig. 1(c) shows a SEM picture of the same sample, with a scale of $2 \mu \mathrm{m}$. It exhibits several big dust particles of a few hundreds of nanometers in diameter that were deposited either during the process or at the plasma extinction. Fig. 1(d) is the same as Fig. 1(c) but taken on a sample located elsewhere on the grounded electrode. It exhibits several dust particle populations. Finally, Fig. 1(a) shows a SEM picture of the same sample as Fig. 1(b) and (c), with a scale of $500 \mathrm{~nm}$, zooming on a "hole" in the layer.

The 3-D dust cloud is trapped in the plasma due to the balance of various forces. At the plasma extinction, most forces are cancelled, except gravity and neutral drag, leading dust grains to fall on the samples. We thus obtain on the samples a quite reliable 2-D image of the 3-D dust cloud. The combination of the four presented images allows one to deduce information concerning the dust cloud structure during the deposition process, and the internal structure of the layer.

By looking at Fig. 1(c) and (d), we observe that various dust populations are present on the samples depending on their location on the grounded electrode. This reveals that the dust cloud is not homogeneous and that the dust particle size is not the same everywhere in the cloud. Moreover, some holes appear in the layer of those figures. They are due to some dust particles that moved when the sample was taken back to atmospheric pressure. When the gas entrance in the chamber is too brutal, big dust particles that are not totally embedded in the layer can be pushed away from their original place, leaving holes of a few hundreds of nanometers in the layer. This last point underlines that some precautions must be taken to take the samples back to atmospheric pressure without damage. Nevertheless, those "holes" in the layer can be quite useful to determine the layer structure.

By comparing Fig. 1(a) and (b), we can show that the layer is made of nanoclusters not only at its surface but also in deep. That means that nanoclusters are deposited all along the process and not only at the plasma extinction. In fact, dust particles immersed in the plasma are stochastically and dynamically charged. Thus, a part of the dust particles constituting the dust cloud are not charged and are deposited continuously on the samples due to the combined effects of gravity and neutral drag force. The hole due to a particle that moved in Fig. 1(a) 


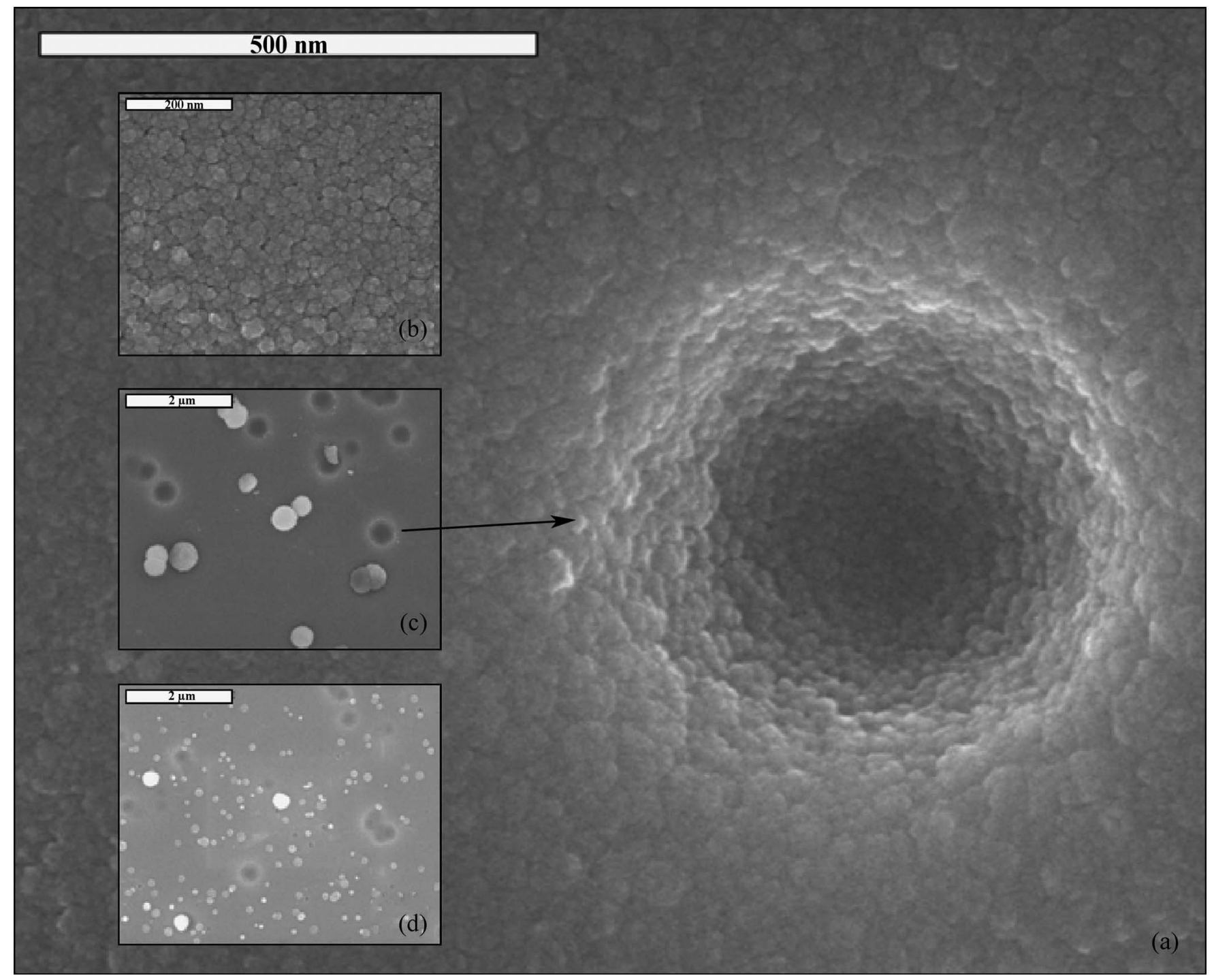

Fig. 1. SEM images of a silicon thin film deposited under dusty plasma conditions. (a) Scale $500 \mathrm{~nm}$ : Hole due to a dust particle that moved. (b) Scale $200 \mathrm{~nm}$ : Compact layer of the thin film. (c) Scale $2 \mu \mathrm{m}$ : Overview of the sample with dust particles and holes in the layer. (d) Scale $2 \mu \mathrm{m}$ : Overview of the various dust particle populations deposited on the sample.

clearly shows that the layer is made of nanoclusters embedded in amorphous silicon.

Finally, Fig. 1 shows a very complete overview of both the dust cloud structure during the deposition under dusty plasma conditions and of the thin layer structure. It shows that the result of depositions performed under dusty plasma conditions depends on the location of the sample in the discharge in terms of deposited dust particles. Moreover, it draws attention on the way samples must be taken to atmospheric pressure. To conclude, it evidences a thin layer made of silicon nanoclusters.

\section{REFERENCES}

[1] L. Boufendi and A. Bouchoule, "Particle nucleation and growth in a lowpressure argon-silane discharge," Plasma Sources Sci. Technol., vol. 3, no. 3, pp. 262-267, Aug. 1994.

[2] M. Cavarroc, M. C. Jouanny, K. Radouane, M. Mikikian, and L. Boufendi, "Self-excited instability occurring during the nanoparticle formation in an $\mathrm{Ar}-\mathrm{SiH}_{4}$ low pressure radio frequency plasma," J. Appl. Phys., vol. 99, no. 6, p. 064 301, Mar. 2006.

[3] M. Cavarroc, M. Mikikian, G. Perrier, and L. Boufendi, "Single-crystal silicon nanoparticles: An instability to check their synthesis," Appl. Phys. Lett., vol. 89, no. 1, p. 013 107, Jul. 2006.

[4] M. Cavarroc, M. Mikikian, Y. Tessier, and L. Boufendi, "Successive generations of dust in complex plasmas: A cyclic phenomenon in the void region," Phys. Rev. Lett., vol. 100, no. 4, p. 045 001, Feb. 2008. 